O. Shashenko, orcid.org/0000-0002-7012-6157, Yu. Golovko, orcid.org/0000-0001-6081-8072, D. Klymenko, orcid.org/0000-0002-4442-9621
Dnipro University of Technology, Dnipro, Ukraine, e-mail: dinklimspring@gmail.com

\title{
RIGIDITY EFFECT OF THE MINE GEOPHONE MOUNTING ON ITS FREQUENCY RESPONSE
}

Purpose. To determine the rigidity effect of the changes in mine geophones mounting on the frequency response of the recorded seismoacoustic signals.

Methodology. Operational calculus and frequency analysis are used.

Findings. The dependences of the frequency characteristics of geophones under coupling conditions with the rock are studied. A possibility is shown of qualitative change in the recorded signal when changing the rigidity of installation of the case of a geophone; moreover, increase in rigidity can result in both increase and decrease in the amplitude of frequency components in a fixed frequency range. The calculations are performed for the parameters characteristic of the current use of geophones and the most common rocks. Electrodynamic velocimeter and piezoelectric accelerometer were considered separately.

Originality. Frequency response changes in the seismoacoustic signal recorded by the geophone can be caused by the changes in the rigidity at the coupling between the geophone and the rock. The ratio of the installation frequency to the natural frequency of the geophone can serve as an indicator of the possible rigidity effect. Numerical values of this indicator are proposed.

Practical value. Critical analysis of the obtained seismoacoustic data, taking into account the possible changes in the geophone installation rigidity in the measurement time. The need to determine the frequency of the geophone mounting in their initial mounting and periodic control to this parameter for further operation.

Keywords: mine geophone, seismoacoustics, frequency response, gas-dynamic phenomena

Introduction. Seismic acoustics occupies a special place among the geophysical methods used in the mining. The obvious advantages of the seismoacoustic method are the ability of obtaining both integral and local data remotely as well as continuous rock monitoring. This determined the main application domains of seismic acoustics in mining, which are the seismic exploration and forecast of gas-dynamic phenomena. The most important component of the seismoacoustic system is a geophone (an inertial-type seismic receiver), which provides the primary transformation of the kinematic parameters of rock oscillations into an electrical signal.

Electrodynamic and piezoelectric seismic receivers are used in mines. Electrodynamic induction (Faraday's law) and the force interaction of the electric current with a magnetic field (Ampere's law) underlie the work of an electrodynamic transducer (velocimeter). The primary electrical signal is proportional to the speed of induction coil relatively to the housing that is permanent magnet. Geophone native frequency is the frequency of the coil mass oscillation (inertial mass) on the elasticity of its suspension.

The basis of the piezoelectric transducer is the direct piezoelectric effect that is the ability of some materials to become electrified under the influence of mechanical stress. Mechanical stress on the piezoelectric elements, respectively the charge on the piezoelectric element surface, arises as a result of the relative housing movement and the inertial mass. The device's natural frequency is the natural frequency of the inertial mass in this case.

The initial process for both types of geophones is the transformation of an external mechanical effect on the housing into a mechanical motion of an inertial mass. This process will be considered further, it determines the vibration meter characteristics.

Electrodynamic transducers are known as velocimeters, and piezoelectric ones are named accelerometers if taking into account the connection of the received electrical signals with the measured kinematic parameters.

The vibration measuring devices based on these principles are used in other areas as well. In particular, to assess the tech-

(C) Shashenko O., Golovko Yu., Klymenko D., 2021 nical condition of machines, mechanisms, structures, means of transport, to monitor the compliance of vibration levels affecting a person. Requirements for their characteristics and use conditions are standardized. A feature of sensor coupling "is that the mechanical coupling between the accelerometer and the structure under test can have a significant effect on the structure response, on the output signal of the accelerometer or both" as indicated in [1]. In this case, the formulated requirements for the structure are quite obvious: "the sensor and its fixing should be as rigid and solid as possible, and the assembly surface should be as clean as possible; ... the sensor mass with the mount should be small in comparison with the dynamic mass of the structure".

These requirements are difficult to satisfy for the mine geophones. The geophone mass cannot be significantly reduced due to the requirements for the safe use of the geophone in conditions of increased gas and dust hazard. In many cases, an available sensor is only a component of the geophone design. Rigidity of the geophone mounting is determined and limited by rock properties in the area of coupling with the geophone. Since the first seismoacoustic studies in mines, researchers have noted a significant influence of the coupling between the geophone housing and the rock in [2, 3]. Producers of vibration meters always pay special attention to this in [4]. New designs of seismic receivers are proposed noting the experimentally discerned dependence on the installation conditions of sensors in $[5,6]$. Producers offer a more rigid ground coupling in these designs in [7]. However, this problem is clearly not paid enough attention in mine seismic acoustics. The industry standard (currently active) that regulates the application of seismoacoustic methods for predicting outburst hazard in coal seams only states that "the seismic receiver is installed ... by wedging in borehole drilled in a coal seam or host rocks. It is allowed to install a seismic receiver by wedging it between the fixing and the rock mass" in [8].

As a rule, the installed geophone is used after or within ten hours after installation in a mine working. The geophone is in coupling with active rock that is undergoing the continuous structural and force changes. During this time, the coupling conditions of the rock mass-geophone housing can change significantly. Often, such changes are evident through clamp- 
ing the geophone in the borehole, the difficulty of extracting, and sometimes geophone loss. In other cases, conclusions are made based on the signals received from the different geophones. It is implicitly assumed that all geophones respond in the same way to identical disturbances.

Oscillations that disseminate in the rock can initiate the propagation of cracks by jump. This effect is possible when the oscillations have a certain frequency range [9]. To control the existence of such oscillations in the vicinity of workings, it is necessary that the installed geophone should have a previously known frequency characteristics.

It is especially important to consider the effect of changing coupling conditions when using methods for predicting hazardous conditions of workings based on the spectral characteristics of the recorded signals [10,11]. In these cases, generally, undistorted registration of oscillations is required in the sufficiently wide frequency interval. The rigidity change in the geophone mounting can lead to the uncontrolled change in such interval and, accordingly, to the false estimation of the hazard.

It follows that knowledge of the nominal frequency range is insufficient and the analysis of the obtained acoustic data must be made taking into account possible changes in the mounting conditions of the seismic receiver.

In this paper we consider the geophone as a linear system with constant parameters and assume the linearity of the coupling between the geophone housing and the rock in particular.

Hence, it is sufficient to have the frequency response $H(f)$ for describing the dynamic properties of the coupling between the rock motions and the reaction of the geophone inertial system. The frequency response $H(f)$ is defined by Fourier Transform on the impulse transfer function $h(t)$

$$
H(f)=\int_{0}^{\infty} h(t) e^{-i \cdot 2 \pi \cdot f \cdot t} \cdot d t .
$$

The frequency interval, where the measurements are considered correct, is defined as an interval, where condition $|H(f)|=1$ is executed with specified accuracy.

The measuring system introduces distortions in the recorded signal that can be estimated if the function $H(f)$ is known. For example, if the recorded oscillations can be considered as stationary random oscillations, then the spectral power densities of the input $G_{x}(f)$ and output $G(f)$ processes (signals) are related by the ratio [12]

$$
G(f)=|H(f)|^{2} \cdot G_{x}(f) .
$$

It is advisable to use this approach for data analysis in systems for assessing the state of workings under acoustic impact on the rock mass by rock-breaking mechanisms in [13].

The purpose of the article is the rigidity effect determination of the changes in mine geophones mounting on the frequency response of the recorded seismoacoustic signals. These changes are caused by the coupling condition changes with oscillating surroundings (rock).

Methodically, we consistently construct a geophone mathematical model as a two-mass system with lumped parameters. We analyze the changes in the frequency characteristics of accelerometers and velocimeters for different installation conditions, determine the values of the initial setting parameters at which changes in contact conditions lead to qualitative changes in the recorded data, and perform estimated calculations with the parameters of real devices.

Main part. We take the calculating scheme of the geophone-rock system shown in Fig. 1, where $M, m$ are the housing mass and inertial element, respectively; $K, A$ are the rigidity and viscosity indicators of the housing-rock coupling, respectively; $k, \alpha$ are the rigidity and viscosity indicators of the geophone elastic element; $x=x(t)$ is a displacement of the inertial element relative to the housing; $y=y(t)$ is a housing displacement relative to the rock; $\xi=\xi(t)$ is a rock displacement relative to the inertial reference system.

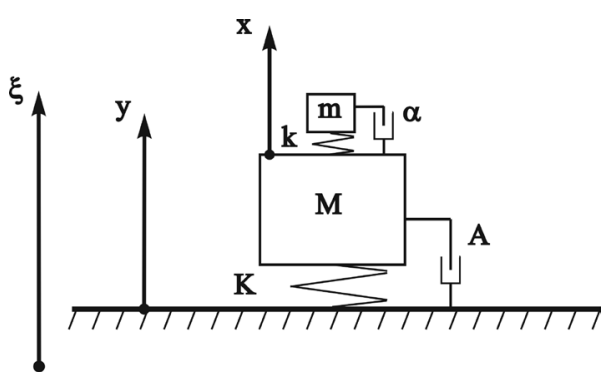

Fig. 1. Calculating scheme of the geophone-rock system

All displacements are only possible to one direction (on the sensitivity axis). The coupling between the housing and the rock is provided at some initial deformation of the system in the initial equilibrium state. Displacements are counted from this initial state. Rigidity index $K$ is determined as the index of the derivative of the contact force with respect to approach in the initial state. System displacement is determined by displacement function $\xi(t)$ that is considered as the external impact.

This simulation also assumes the following assumptions: the geophone housing is absolutely rigid; the length of the body $l$, the velocity of longitudinal oscillations $c_{p}$ in the rock and the highest frequency $f_{m}$ of the function harmonic component $\xi(t)$ are related by the ratio $l \cdot f_{m} \ll c_{p}$; the geophone displacements does not effect on $\xi(t)$; the deviations of the system from the equilibrium state are small and admit linearization of the dependence of the contact interaction force on the approach of the contacting bodies.

The motion equations for the housing and inertial mass are

$$
\begin{gathered}
-M \cdot \frac{d^{2}}{d t^{2}}(y+\xi)-K \cdot y-A \cdot \frac{d y}{d t}+k \cdot x+\alpha \cdot \frac{d x}{d t}=0 ; \\
-m \cdot \frac{d^{2}}{d t^{2}}(y+x+\xi)-k \cdot x-\alpha \cdot \frac{d x}{d t}=0 .
\end{gathered}
$$

Let us introduce the notations

$$
\begin{gathered}
\omega_{0}^{2}=\frac{k}{m} ; \quad \Omega_{0}^{2}=\frac{K}{M} ; \\
W_{0}=\frac{\Omega_{0}}{\omega_{0}} ; \quad \mu=\frac{m}{M} ; \quad \lambda=\frac{\alpha}{2 m \cdot \omega_{0}} ; \quad \Lambda=\frac{A}{2 M \cdot \Omega_{0}}
\end{gathered}
$$

and choose as the time scale $\frac{1}{\omega_{0}}$ (then $t$ is a non-dimensional variable), systems $(1,2)$ have the form

$$
\begin{gathered}
\frac{d^{2} y}{d t^{2}}+2 W_{0} \cdot \Lambda \cdot \frac{d y}{d t}+W_{0}^{2} \cdot y-2 \mu \cdot \lambda \cdot \frac{d x}{d t}-\mu \cdot x=-\frac{d^{2} \xi}{d t^{2}} \\
\frac{d^{2} y}{d t^{2}}+\frac{d^{2} x}{d t^{2}}+2 \lambda \cdot \frac{d x}{d t}+x=-\frac{d^{2} \xi}{d t^{2}} .
\end{gathered}
$$

Then, if $\frac{d^{2} \xi}{d t^{2}}=\delta_{1}(t)$, where $\delta_{1}(t)$ is unit impulse function of Dirac $\delta_{1}(t)=\left\{\begin{array}{ll}\infty, & t=0 \\ 0, & t \neq 0\end{array} ; \quad \int_{-\infty}^{+\infty} \delta_{1}(t) d t=1\right.$, we pass to the Fourier images in system $(5,6)$ and solve the resulting system, we obtain the frequency response $X(W)$ for the mechanical system reaction of the geophone in the form of a displacement $x$ to external acceleration $\frac{d^{2} \xi}{d t^{2}}$ (input is an acceleration, output is a displacement)

$$
X(W)=\frac{W_{0}^{2}+i \cdot 2 \Lambda W_{0} W}{-W^{4}+S_{1} \cdot W^{2}-W_{0}^{2}+i \cdot 2 W \cdot\left(S_{2} W^{2}-S_{3}\right)},
$$


where $S_{1}=S_{1}\left(W_{0}, \mu, \Lambda, \lambda\right)=W_{0}^{2}+4 \cdot \Lambda \cdot \lambda \cdot W_{0}+\mu+1 ; S_{2}=S_{2}\left(W_{0}\right.$, $\mu, \Lambda, \lambda)=W_{0} \cdot \Lambda+(\mu+1) \lambda ; S_{3}=S_{3}\left(W_{0}, \mu, \Lambda, \lambda\right)=W_{0} \cdot\left(\lambda \cdot W_{0}+\right.$ $+\Lambda$ ); $W$ is non-dimensional frequency (scale is $\omega_{0}$ ).

Amplitude-frequency response is

$$
|X(W)|=\frac{W_{0} \cdot \sqrt{W_{0}^{2}+4 \cdot \Lambda^{2} \cdot W^{2}}}{\sqrt{\left(W^{4}-S_{1} \cdot W^{2}+W_{0}^{2}\right)^{2}+4 W^{2} \cdot\left(S_{2} W^{2}-S_{3}\right)^{2}}} .
$$

Phase-frequency response can found by the formula

$$
\varphi_{X}(W)=\varphi_{*}[\operatorname{Re}(X(W)), \operatorname{Im}(X(W))],
$$

where $\varphi_{*}(x, y)=2 \operatorname{arctg}\left(\frac{y}{x+\sqrt{x^{2}+y^{2}}}\right)$.

Considering that the electrical signal is proportional to the deformation of the piezoelectric element in a piezoelectric accelerometer, (7, 8 and 9) are frequency responses of this seismic receiver type.

The electrical signal is proportional to the speed of inertial mass displacement in the electrodynamic velocimeter. In this case, the frequency response $V(W)$ demonstrates connection between the strain rate $\frac{d x}{d t}$ of the external effect speed $\frac{d \xi}{d t}$.

We get the desired function $V(W)$ when we differentiate the geophone reaction image and take integral of the external effect image

$$
V(W)=\frac{i W \cdot X(W)}{\frac{1}{i W}}=-W^{2} \cdot X(W) .
$$

Amplitude-frequency and phase-frequency responses are, respectively

$$
|V(W)|=W^{2} \cdot|X(W)| ;
$$

$\varphi_{V}(W)=\varphi_{*}[\operatorname{Re}(V(W)), \operatorname{Im}(V(W))]=\varphi_{X}(W)-\pi$.

Frequency responses in (6-12) depend on the dimensionless frequency and four dimensionless complexes defined in (4): $\mu, \lambda, \Lambda, W_{0}$.

The complexes have an obvious physical meaning involving the following: $\mu$ is the ratio of the inertial element mass to the body mass (reduced mass); $\lambda, \Lambda$ are damping indicators characterizing energy dissipation on the internal and external connections of the seismic receiver; $W_{0}$ is the ratio of the installation frequency to the rated frequency of the inertial mass.

Then we mainly analyze the amplitude-frequency responses. Let us first consider two of the most simply analyzed cases:

a) absolute rigidity of installation. $W_{0} \rightarrow \infty$. We find the limit as $W_{0} \rightarrow \infty$ in (8) using relation (11) and we get

$$
\begin{gathered}
|X(W)|=\frac{1}{\sqrt{1+W^{4}+4 W^{2} \cdot \lambda^{2}-2 W^{2}}} \\
|V(W)|=\frac{1}{\sqrt{1+\frac{1}{W^{4}}+\frac{2 \cdot\left(2 \lambda^{2}-1\right)}{W^{2}}}} .
\end{gathered}
$$

Formulas $(13,14)$ coincide with formulas for a single-mass oscillator. Note that the factor $\frac{1}{\omega_{0}^{2}}$ appears in (13) upon passing to the dimensional quantities;

b) damping is absent. $\Lambda=\lambda=0$.

We find two natural frequencies for $W>0$, when the denominator in expression (8) is equal to zero

$$
W_{1}=\frac{1}{\sqrt{2}} \cdot \sqrt{1+W_{0}^{2}+\mu-\sqrt{\left(W_{0}^{2}+\mu-1\right)^{2}+4 \mu}}
$$

$$
W_{2}=\frac{1}{\sqrt{2}} \cdot \sqrt{1+W_{0}^{2}+\mu+\sqrt{\left(W_{0}^{2}+\mu-1\right)^{2}+4 \mu}} .
$$

Obviously, $W_{1} \leq W_{2}$. This equality may be used for $\mu=0$, $W_{0}=1$.

The natural frequency difference grows as $\mu$ increases and $\left|W_{0}^{2}-1\right|$, can be approximately calculated by the formula

$$
W_{2}-W_{1} \approx \frac{\sqrt{\mu} \cdot\left(1-\frac{\mu}{8}\right)}{1+\left(W_{0}-1\right)^{2}}+\left|W_{0}-1\right|,
$$

when $\mu \leq 0.5$, the difference between (17) and the exact value does not reach above than 0.18 , and when $\mu \leq 0.05$, this difference is no more than 0.11 .

Further, we shall investigate separately the frequency responses of the piezo accelerometer and the electrodynamic velocimeter.

Accelerometer (pre-resonance mode). Input is an acceleration of the rock and output (signal) is a deformation of an elastic element (piezoelectric element). Frequency responses are calculated by the formulas $(8,9)$.

The energy dissipation at the strain of commonly used piezoelectric elements is insignificant and damping is usually not taken into account when calculating accelerometers. Thus, we suppose that the value $\lambda$ is the constant, by setting $\lambda=0.01$.

Increasing the mass of the accelerometer allows for increased sensitivity, but at the same time leads to a narrowing of the frequency range. For mine accelerometers, dimensionless complex is $\mu<0.05$. Further we take into account this condition.

The magnitude of the frequency response differs from 1 by no more than 0.1 with an absolutely rigid installation, if the frequency is less than 0.3 of the natural frequency of the accelerometer. At the accepted scale, this interval corresponds to $W \in(0 ; 0.3)$. We call this frequency interval "working", since it is in this interval that measurements can be made without taking into account the peculiarities of the geophone installation.

Let us first consider the cases where $W_{0} \geq 1$.

Amplitude-frequency and phase-frequency responses of the accelerometer are in Fig. 2. Resonance frequencies have insignificant differences from 1 and $W_{0}$, also have yet more insignificant differences from $W_{1}$ and $W_{2}$ that are calculated by $(15,16)$.

The rigidity changes in the geophone installation are presented in Fig. 3. With rigidity growth we have amplitude-frequency response approximate to amplitude-frequency response with account the natural frequency of the geophone only. If the rigidity decreases, even without becoming less than one, the differences from the amplitude values of the frequency response increase noticeably in the "working" frequency range $W \in(0 ; 0.3)$ (Fig. 3, $b$ ). This leads to an increase in the recorded signal, first of all, the components related to the end of a given frequency interval.

Calculations showed that when $\mu \geq 0.1, \Lambda \leq 0.5$, then the effect of the relative mass and the damping factor can be ne-

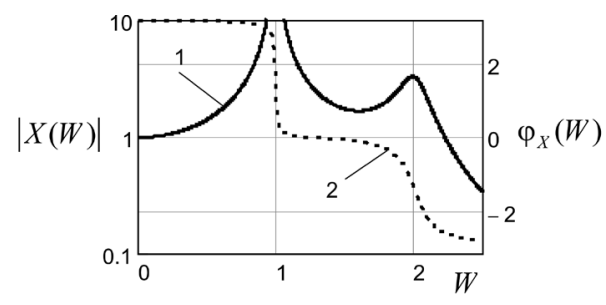

Fig. 2. Amplitude-frequency (1) and phase-frequency responses (2) of the accelerometer at: $W_{0}=2 ; \mu=0.03 ; \lambda=0.01 ; \Lambda=0.05$ 


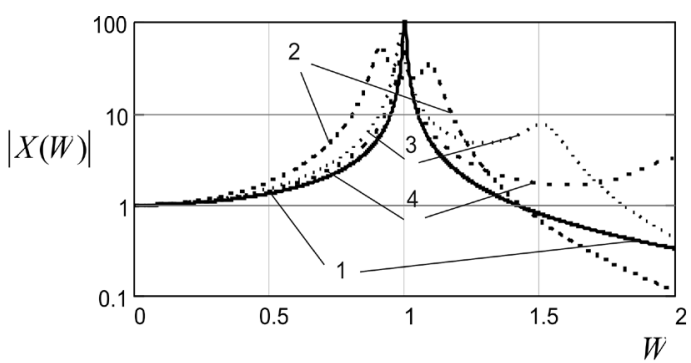

$a$

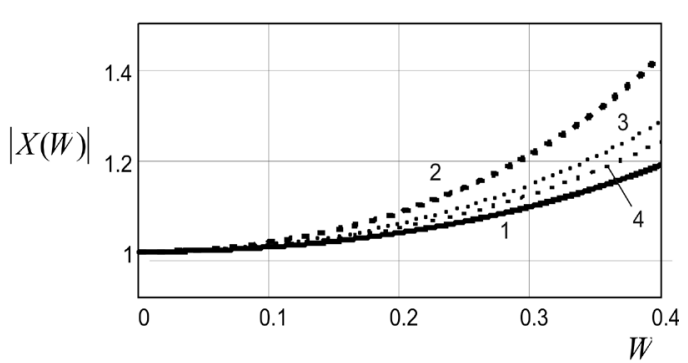

$b$

Fig. 3. Amplitude-frequency response of the accelerometer at different values $W_{0} \geq 1$ :

$1-W_{0} \rightarrow \infty$ (absolutely rigid geophone installation); $2-W_{0}=1 ; 3-W_{0}=1.5 ; 4-W_{0}=2$, at $\left.\mu=0.04, \lambda=0.01, \Lambda=0.05 ; a\right) W \in(0 ; 3)$; b) $W \in(0 ; 0.4)$

glected if we assume $\mu=0, \Lambda=0$. As a result, the greatest error is on the end of the "working" interval and it is no more than 0.01 . Thus, when $W_{0}>1$, the effect of the geophone installation on the amplitude-frequency response can be evaluated only based on the value $W_{0}$.

Let $W_{0}<1$. In this case, the critical frequency is not equal to the natural frequency of the geophone $(W=1)$, the frequency $W_{0}$ and components with frequencies higher than value $0.3 \cdot W_{0}$ will be recorded with great distortions (Fig. 4). The growth of the rigidity of the installation, as well as at $W_{0} \geq 1$, leads to a decrease in the deviation of the amplitude-frequency response from 1 over the entire "working" frequency range. And if in the initial position the maximum of the amplitudefrequency response is outside this interval, then also lowering the rigidity of the installation leads to overestimation of the recorded values of the components with higher frequencies.

However, another situation is also possible here. If in the initial position the maximum of the amplitude-frequency re- sponse is inside "working" frequency range, then at increasing the rigidity of the installation this maximum moves towards higher frequencies interval (Fig. $4, b$ ). Thus, the overestimation of the values of the components with higher frequencies can be observed at increasing the rigidity of the installation.

The effect of the relative mass at $\mu \leq 0.1$ is insignificant and only first resonance frequency (frequency of the installation) moves. The growth of the in damping factor $\Lambda$ is essential for changes in the amplitude-frequency response and in result is the lowering the extreme value of the first resonance and, as it was, stretching the curve along the frequency axis (Fig. 5). However, all remarks on possible changes in the registration of frequency components remain valid when changing the rigidity of the installation.

Velocimeter (post-resonance mode). Input is a velocity of the rock, output (signal) is a velocity of the inertial mass (coil). Frequency response is calculated by the formulas $(11,12)$.

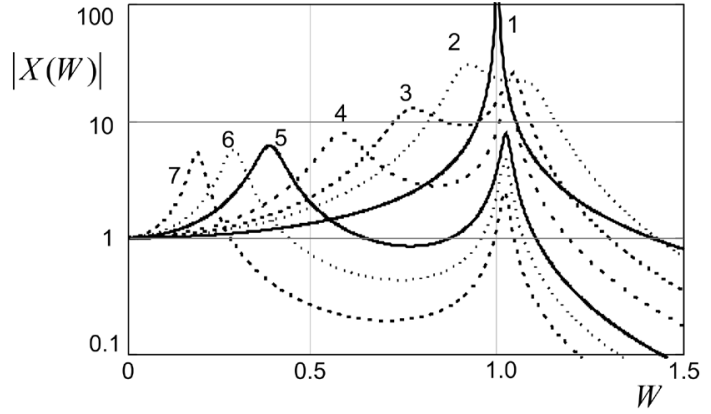

$a$

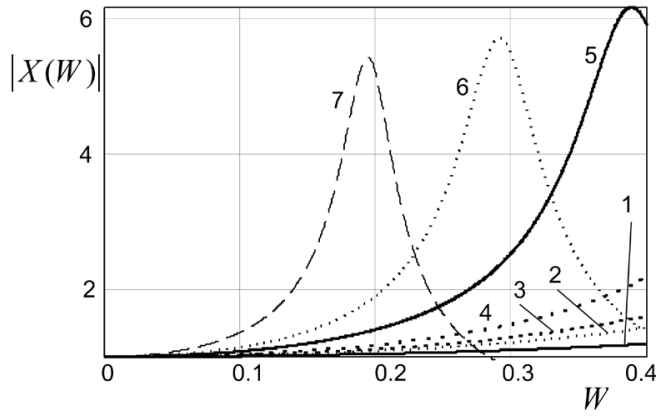

$b$

Fig. 4. Amplitude-frequency response of the accelerometer at different values $W_{0}<1$ :

$1-W_{0} \rightarrow \infty$ (absolutely rigid geophone installation $) ; 2-W_{0}=1 ; 3-W_{0}=0.8 ; 4-W_{0}=0.6 ; 5-W_{0}=0.4 ; 6-W_{0}=0.3 ; 7-W_{0}=0.2$, at $\mu=$ $=0.04, \lambda=0.01, \Lambda=0.1 ; a) W \in(0 ; 3) ; b) W \in(0 ; 0.4)$

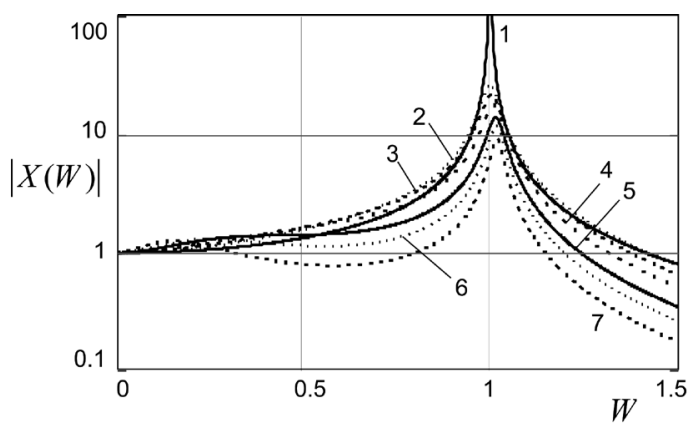

$a$

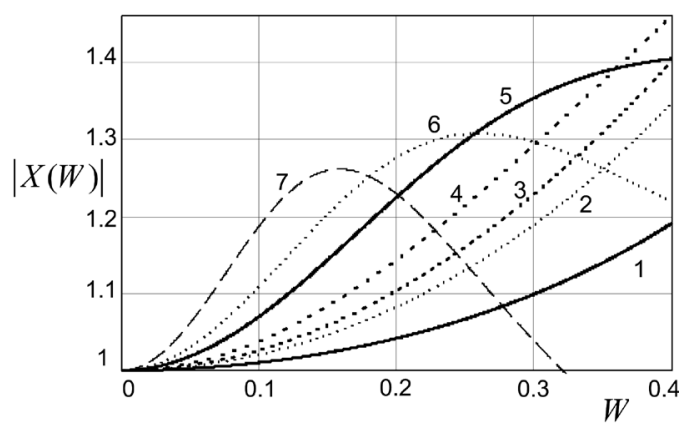

$b$

Fig. 5. Amplitude-frequency response of the accelerometer at different values $W_{0}<1$ and damping factor $\Lambda=0.8$ :

$1-W_{0} \rightarrow \infty$ (absolutely rigid geophone installation) $; 2-W_{0}=1 ; 3-W_{0}=0.8 ; 4-W_{0}=0.6 ; 5-W_{0}=0.4 ; 6-W_{0}=0.3 ; 7-W_{0}=0.2$, at $\mu=$ $=0.04, \lambda=0.01 ; a) W \in(0 ; 3) ; b) W \in(0 ; 0.4)$ 
Amplitude-frequency and phase-frequency responses of the velocimeter (post-resonance mode) are shown in Fig. 6.

If we do not take into account the rigidity of the installation, then the amplitude-frequency response has one extremum when $W \approx 1$. The beginning of the "working" interval is defined as a point on the frequency axis where the amplitude-frequency response differs from 1. Damping is used to expand the interval towards lower frequencies. Damping is considered optimal when the resonance rise on the frequency response curve does not exceed 1 with a given accuracy. Typically, this requires that $\lambda \in(0.5 ; 0.7)$. The required level of damping is achieved by selection of resistance, closing the induction coil. In this case, the Ampere force can be approximately represented as the product of a constant and coil velocity relative to the geophone housing, that is, in the form accepted in the model $(1,2)$.

The value of the damping factor $\lambda$ is chosen significantly less than the optimal value in order to visualize the first resonance in Fig. 6 . Further, let $\lambda=0.7$. Then the beginning of the "working" interval can be accepted as native frequency of the geophone.

The measurement interval within the framework of this model (without taking into account the effect of the rigidity installation) is not bounded above. In real devices, the limitation is due to the presence of secondary resonances, the effect of which is eliminated by low-frequency electric filters with a cutoff frequency at the level of 100-150 natural frequencies of the geophone. Based on this, we consider $W<150$.

The amplitude-frequency response for different values $W_{0}$ is shown in Fig. 7. With an increase in the rigidity of the installation, the second extremum moves towards an increase in frequency, the maximum value of the amplitude-frequency response changes insignificantly. There is an abrupt drop in amplitude-frequency response, similar to the drop formed by a low-frequency filter when $W>W_{0}$.

The calculations showed that a change in the value of reduced mass $\mu$ significantly affects the amplitude-frequency response only at values $W_{0}<10$. The effect of the damping factor $\Lambda$ is more significant. Fig. 8 shows curves for which, in comparison with the curves in Fig. 7, only values $\Lambda$ have changed. The effect of the value $\Lambda$, similarly the effect of the value $\lambda$, leads to a decrease in the extreme value, only corresponding not to its own, but to the installation resonance. And drop of the amplitude-frequency response is at $W>W_{0}$.

When changing the installation parameters for the velocimeter, as well as when changing the installation parameters for the accelerometer (considered above), two situations are possible. If the values $W_{0}$ do not belong to the "working" frequency interval, then a decrease in the rigidity of the installation leads to an increase in the amplitudes of the high-frequency components. If the initial values $W_{0}$ belong to the "working" frequency interval, then a bandwidth boost filter is formed. With an increase in the rigidity of the installation, the bandwidth moves towards an increase in frequency that entails an increase in the high-frequency components in the recorded signal. These changes are in the geophone vicinity at the rock movement.

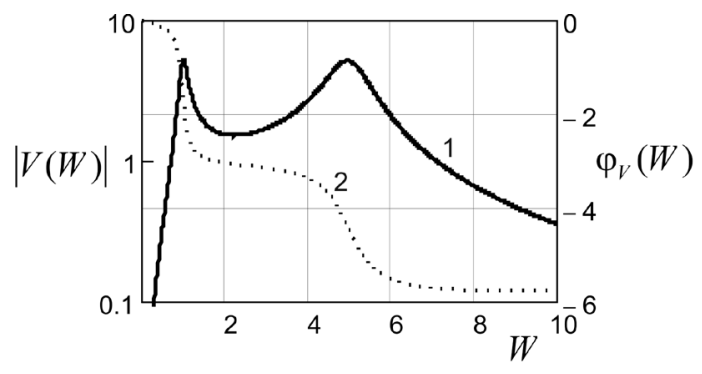

Fig. 6. Amplitude-frequency (1) and phase-frequency responses (2) of the velocimeter at:

$W_{0}=2 ; \mu=0.03 ; \lambda=0.01 ; \Lambda=0.05$

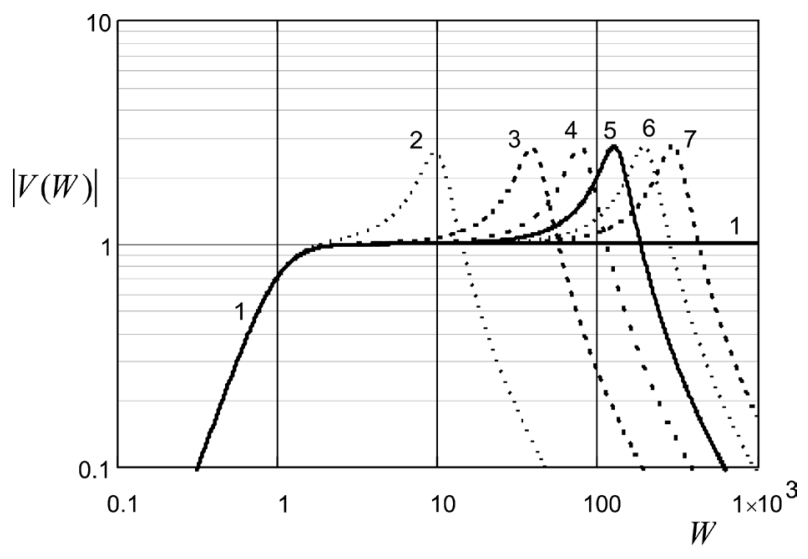

Fig. 7. Amplitude-frequency response of the velocimeter at different values $W_{0}$ :

$1-W_{0} \rightarrow \infty$ (absolutely rigid geophone installation); $2-W_{0}=10$; $3-W_{0}=20 ; 4-W_{0}=40 ; 5-W_{0}=60 ; 6-W_{0}=100 ; 7-W_{0}=$ $=150$ at $\mu=0.2 ; \lambda=0.7 ; \Lambda=0.2$

As can be seen the qualitative changes in amplitude-frequency response of the accelerometer or velocimeter are observed for certain values of the dimensionless complex $W_{0}$.

Three types of initial states of the geophone installation can be identified, for each of which an increase in the rigidity will lead to qualitatively different changes in the spectra of recorded signals. The transition from one type of the initial state to another is associated with the increase in $W_{0}$. We call the limitary values $W_{0}$ as $W_{01}$ and $W_{02}$.

I. $W_{0}<W_{01}$. Extremum of the amplitude-frequency response belongs to the "working" frequency range of the geophone. In the initial state, the components belonging to the "working" frequency range have the resonant maxima. The increase in the rigidity of the installation leads to the increase in high-frequency components.

II. $W_{01}<W_{0}<W_{02}$. Extremum of the amplitude-frequency response does not belong to the "working" frequency range of the geophone. The growth in high-frequency components occurs at the decrease in the rigidity of the installation.

III. $W_{0}>W_{02}$. The effect of the rigidity of the installation on the frequency components is insignificant.

The limitary values $W_{01}$ and $W_{02}$ are shown below. For accelerometer, they are $W_{01}=0.25$ and $W_{02}=2$. For velocimeter, they are $W_{01}=60$ and $W_{02}=200$.

Further, we evaluate the possible values $W_{0}$ for the typical geophones. We make the following assumptions and accept the following notations when calculating the rigidity of the installation. Geophone housing is a non-deformable cylinder of the radius $R$. Geophone is mounted in the borehole using the wedging method. One end of the housing couples with the rock, and the other end couples with the wedging insert. The rock coupling surfaces and wedging inserts are flat, perpendicular to the chamber axis.

To estimate the coupling effects, we use the solution of the problem of the embedding round plan stamp into the elastic half-space. Then the dependence between the convergence $\delta_{0}$ and the normally acting force $F$ (Rabotnov Yu., 1988) is $\delta_{0}=\frac{F\left(1-v^{2}\right)}{2 E R}$, where $E, v$ are elastic modulus and Poisson's ratio for the elastic half-space.

We represent the convergence as the sum of the initial convergence $\delta_{0}$ that occurred during the initial wedging, and $y$ is the small value that is due to the motion by rock oscillation. From quasi-static theory, the dependence between the contact force $F$ and convergence $\delta_{0}+y$ can be written as $F=\frac{2 E R\left(\delta_{0}+y\right)}{\left(1-v^{2}\right)}$.

Then rigidity ratio in contact with something is 


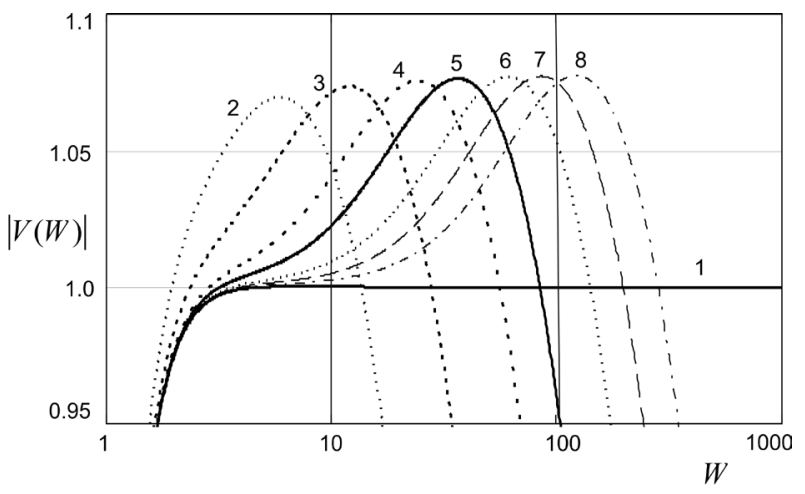

Fig. 8. Amplitude-frequency response of the velocimeter at different values $W_{0}$ and at increasing value $\Lambda=1.5$ :

$1-W_{0} \rightarrow \infty$ (absolutely rigid geophone installation); $2-W_{0}=10$; $3-W_{0}=20 ; 4-W_{0}=40 ; 5-W_{0}=60 ; 6-W_{0}=100 ; 7-W_{0}=$ $=150$, at $\mu=0.2 ; \lambda=0.7$

$$
K_{k}=\left.\frac{d F}{d y}\right|_{y=0}=\frac{2 E R}{\left(1-v^{2}\right)} .
$$

The rigidity ratio for geophone $K$ equals the sum of the rigidity ratio to couple with the rock $K_{r}$ and the rigidity ratio to couple with the insert $K_{i n}: K=K_{r}+K_{i n}$, where each of the coefficients is calculated with the corresponding values of $E$ and $v$ for the rock types and insert materials according to (18).

Usually geophones are mounted in the boreholes with a diameter of $0.042 \mathrm{~m}$. Calculations were carried out at the maximum possible value: $R=0.02 \mathrm{~m}$. Mechanical parameters of rocks are taken from $[14,15]$. Insert material parameters are the same in all cases: $E=0.5 \mathrm{GPa}, v=0.49$ (pinetree) [16].

The selection of the value of the circular frequency $\omega_{0}$ links the corresponding calculation with the geophone type at $W_{0}$ calculates. For the accelerometer we choose the values

Values $W_{0}$ for different rock types and geophone masses

\begin{tabular}{|c|c|c|c|c|c|c|c|c|}
\hline \multirow{2}{*}{ Rock types } & \multirow{2}{*}{$K_{r}, \frac{\mathrm{GN}}{\mathrm{m}}$} & \multirow{2}{*}{$\frac{\omega_{0}}{2 \pi}, \mathrm{Hz}$} & \multicolumn{6}{|c|}{$W_{0}$} \\
\hline & & & $m=0.7 \mathrm{~kg}$ & $m=0.5 \mathrm{~kg}$ & $m=0.3 \mathrm{~kg}$ & $m=0.2 \mathrm{~kg}$ & $m=0.1 \mathrm{~kg}$ & $m=0.05 \mathrm{~kg}$ \\
\hline \multirow{3}{*}{$\begin{array}{l}\text { Aleurolite, } E=30 \mathrm{GPa}, \\
v=0.2 \text { in }[14]\end{array}$} & 1.250 & 30000 & 0.227 & 0.268 & 0.346 & 0.424 & 0.599 & 0.848 \\
\hline & 1.250 & 20000 & 0.340 & 0.402 & 0.519 & 0.636 & 0.899 & 0.271 \\
\hline & 1.250 & 10000 & 0.680 & 0.804 & 1.038 & 1.271 & 1.798 & 2.543 \\
\hline \multirow{3}{*}{$\begin{array}{l}\text { Sandstone, } E=20 \mathrm{GPa} \\
\nu=0.25 \text { in }[14]\end{array}$} & 0.853 & 30000 & 0.188 & 0.223 & 0.287 & 0.352 & 0.498 & 0.704 \\
\hline & 0.853 & 20000 & 0.282 & 0.334 & 0.431 & 0.528 & 0.746 & 1.056 \\
\hline & 0.853 & 10000 & 0.564 & 0.668 & 0.862 & 1.056 & 1.493 & 2.111 \\
\hline \multirow{3}{*}{$\begin{array}{l}\text { Limestone, } E=6 \mathrm{GPa}, \\
v=0.27 \text { in }[14]\end{array}$} & 0.259 & 30000 & 0.107 & 0.127 & 0.164 & 0.200 & 0.283 & 0.401 \\
\hline & 0.259 & 20000 & 0.161 & 0.190 & 0.245 & 0.300 & 0.425 & 0.601 \\
\hline & 0.259 & 10000 & 0.321 & 0.380 & 0.491 & 0.601 & 0.850 & 1.202 \\
\hline \multirow{3}{*}{$\begin{array}{l}\text { Coal, } E=1 \mathrm{GPa}, v=0.1 \\
\text { in [14] }\end{array}$} & 0.040 & 30000 & 0.052 & 0.061 & 0.079 & 0.097 & 0.137 & 0.194 \\
\hline & 0.040 & 20000 & 0.078 & 0.092 & 0.119 & 0.145 & 0.206 & 0.291 \\
\hline & 0.040 & 10000 & 0.155 & 0.184 & 0.237 & 0.291 & 0.411 & 0.581 \\
\hline \multirow{3}{*}{$\begin{array}{l}\text { Coal, } E=7.5 \mathrm{GPa}, \\
v=0.43 \text { in }[15]\end{array}$} & 0.020 & 30000 & 0.126 & 0.149 & 0.192 & 0.236 & 0.333 & 0.471 \\
\hline & 0.020 & 20000 & 0.189 & 0.223 & 0.289 & 0.353 & 0.500 & 0.707 \\
\hline & 0.020 & 10000 & 0.378 & 0.447 & 0.577 & 0.707 & 1.000 & 1.413 \\
\hline \multirow{3}{*}{$\begin{array}{l}\text { Aleurolite, } E=30 \mathrm{GPa}, \\
\nu=0.2 \text { in [14] }\end{array}$} & 1.250 & 40 & 169.9 & 201.0 & 259.5 & 317.9 & 449.5 & 635.7 \\
\hline & 1.250 & 30 & 226.5 & 268.0 & 346.0 & 423.8 & 599.3 & 847.6 \\
\hline & 1.250 & 20 & 339.8 & 402.1 & 519.0 & 635.7 & 899.0 & 1271.4 \\
\hline \multirow{3}{*}{$\begin{array}{l}\text { Sandstone, } E=20 \mathrm{GPa} \text {, } \\
v=0.25 \text { in [14] }\end{array}$} & 0.853 & 40 & 141.0 & 166.9 & 215.5 & 263.9 & 373.2 & 527.8 \\
\hline & 0.853 & 30 & 188.1 & 222.5 & 287.3 & 351.8 & 497.6 & 703.7 \\
\hline & 0.853 & 20 & 282.1 & 333.8 & 430.9 & 527.8 & 746.4 & 1055.5 \\
\hline \multirow{3}{*}{$\begin{array}{l}\text { Limestone, } E=6 \mathrm{GPa}, \\
v=0.27 \text { in }[14]\end{array}$} & 0.259 & 40 & 80.3 & 95.0 & 122.7 & 150.2 & 212.5 & 300.5 \\
\hline & 0.259 & 30 & 107.1 & 126.7 & 163.6 & 200.3 & 283.3 & 400.7 \\
\hline & 0.259 & 20 & 160.6 & 190.1 & 245.4 & 300.5 & 425.0 & 601.0 \\
\hline \multirow{3}{*}{$\begin{array}{l}\text { Coal, } E=1 \mathrm{GPa}, v=0.1 \\
\text { in [15] }\end{array}$} & 0.040 & 40 & 38.8 & 46.0 & 59.3 & 72.7 & 102.8 & 145.3 \\
\hline & 0.040 & 30 & 51.8 & 61.3 & 79.1 & 96.9 & 137.0 & 193.8 \\
\hline & 0.040 & 20 & 77.7 & 91.9 & 118.7 & 145.3 & 205.6 & 290.7 \\
\hline \multirow{3}{*}{$\begin{array}{l}\text { Coal, } E=7.5 \mathrm{GPa}, \\
v=0.43 \text { in }[15]\end{array}$} & 0.0200 & 40 & 94.4 & 111.7 & 144.3 & 176.7 & 249.9 & 353.4 \\
\hline & 0.0200 & 30 & 125.9 & 149.0 & 192.3 & 235.6 & 333.2 & 471.2 \\
\hline & 0.0200 & 20 & 188.9 & 223.5 & 288.5 & 353.4 & 499.7 & 706.7 \\
\hline
\end{tabular}


$\frac{\omega_{0}}{2 \pi}=30 \mathrm{KHz}, 20 \mathrm{KHz}, 10 \mathrm{KHz}$, for the velocimeter we choose the values $\frac{\omega_{0}}{2 \pi}=40 \mathrm{~Hz}, 30 \mathrm{~Hz}, 20 \mathrm{~Hz}$.

The results of the calculations are represented in Table. The data related to the first type of geophone installation are highlighted in boldface, and the data related to the second type are in italics. Obviously, in these cases, the measurement results require a special analysis, taking into account the revealed features, both in the initial state and with possible changes in the rigidity of the installation. So, the growth of high-frequency components in the recorded signal can be caused only by changes in the rigidity of the coupling between the geophone housing and rock types, that is, to characterize the local changes in the stress-strain state in rock mass. The assumptions made in calculating the rigidity ratio (non-deformability of the geophone housing, the maximum possible radius of the chamber, idealization of the coupling conditions with the rock) lead, most likely, to overestimated values of $K$, and hence, $W_{0}$. Therefore, the effect of the rigidity installation on the parameters recorded by the geophone can be even more significant than it follows from the data in the table. The above results indicate the need to determine the frequency of the geophone installation during their initial installation and to periodically control this parameter during further operation. The obtained values should be taken into account when interpreting and analyzing the recorded signals.

Conclusions. The frequency response analysis of the twomass mathematical model of the geophone is carried out taking into account the coupling conditions with the rock.

The characteristics for geophones used in pre resonant and post resonant modes are considered. It is shown that with a change in the rigidity of the coupling between the geophone housing and the rock, both an increase and a decrease in highfrequency components in the recorded seismoacoustic signal are possible. As an indicator of such situations, you can use the ratio of the installation frequency to the natural frequency of the geophone.

Numerical values of this indicator are proposed, both for an electrodynamic velocimeter and for a piezoelectric accelerometer. Calculations are given at geophones installed in a hole. The necessity of periodic monitoring of the geophones mounting frequency is represented when using geophones.

The above results can be used both in the development of new geophones and in the critical analysis of previously obtained data.

\section{References.}

1. GOST ISO 5348-2002. Vibration and shock. Mechanical mounting of accelerometers (n.d.). Retrieved from http://docs.cntd.ru/document/ gost-iso-5348-2002.

2. Glikman, A. G. (n.d.). Spectral seismic prospecting - origins and consequences. Retrieved from https://newgeophys.spb.ru/ru/book2/1-1. shtml.

3. Pamukcu, S., \& Cheng, L. (Eds.) (2018). Underground Sensing. Monitoring and Hazard Detection for Environment and Infrastructure. Retrieved from https://www.sciencedirect.com/science/article/pii/ B9780128031391000035.

4. Piezoelectric Accelerometers and Vibration Preamplifiers. Theory and Application Handbook (n.d.). Briiel \& Kiar. Retrieved from https:// www.bksv.com/doc/bb0694.pdf.

5. Wei, Z., \& Hall, M.A. (2011). Analyses of vibrator and geophone behavior on hard and soft ground. The Leading Edge, 30(2), 132-137. https://doi.org/10.1190/1.3555320.

6. Segarra, P., Sanchidrián, J.A., Castedo, R., \& del Castillo, I. (2017). Coupling of blasting seismographs to rock and its effectiveness for horizontal ground motion. International Journal of Rock Mechanics and Mining Sciences, 92, 81-90.

7. Wang, Y., Fu, N., Fu, Z., Lu, X., Liao, X., Wang, H., \& Qin, S. (2019). A Semi-Automatic Coupling Geophone for Tunnel Seismic Detection. Sensors, 19, 3734. https://doi.org/10.3390/s19173734.
8. Ministry of Coal Industry of Ukraine (2005). Standard SOU 10.1.00174088.011-2005. Rules of mining in seams prone to gas-dynamic phenomena. Retrieved from https://ua1lib.org/book/2445170/5 2b7ed? regionChanged $=\&$ redirect $=240256942$.

9. Korol, V. I., \& Skobenko, A. V. (2013). Acoustic method for forecasting gas-dynamic phenomena in coal mines: monograph. Dnipropetrovsk: National Mining University.

10. Kopylov, K. N., Smirnov, O. V., \& Kulik, A. I. (2015). Acoustic monitoring of the state of the massif and forecast of dynamic phenomena. Bezopasnost truda v promyshlennosti, (8), 32-37.

11. Sdvyzhkova, O., Golovko, Y., \& Klymenko, D. (2017). Effect of harmonic oscillations on a crack initiation in the rock mass. Naukovyi Visnyk Natsionalnoho Hirnychoho Universytetu, (4), 13-18.

12. Bendat, J., \& Piersol, A. (2010). Random Data: Analysis and Measurement Procedures ( $4^{\text {th }}$ ed.). Wiley. ISBN: 978-0-470-24877-5.

13. Golovko, Yu. N. (2017). Evaluation of spectral parameters of seismoacoustic signals in the latest estimate of gas-dynamic phenomena in mines. Geo-Technical Mechanics, Collection of Scientific Papers, 134, 141-154.

14. Shashenko, A. N., Maikherchik, T., \& Sdvizhkova, Ye.A. (2012). Geomechanical processes in rock masses: monograph.

15. Guo, W.-Y., Tan, Yu., Yu, F.-H., \& Zhao, T.-B. (2018). Mechanical behavior of rock-coal-rock specimens with different coal thicknesses. Geomechanics and Engineering, 15(4), 1017-1027. https://doi. org/10.12989/gae.2018.15.4.1017.

\section{Вплив жорсткості установки шахтного геофону на його частотну характеристику}

\section{О. М. Шашенко, Ю. М. Головко, Д. В. Клименко}

Національний технічний університет «Дніпровська політехніка», м. Дніпро, Україна, e-mail: dinklimspring@ gmail.com

Мета. Визначити вплив змін жорсткості установки шахтних геофонів на характеристики зареєстрованих сейсмоакустичних сигналів.

Методика. Використані операційне числення та частотний аналіз.

Результати. Досліджені залежності частотних характеристик геофонів за різних умов контакту між геофоном і гірською породою. Показана можливість якісної зміни зареєстрованого сигналу при зміні жорсткості установки корпусу геофону, причому підвищення жорсткості може призводити як до збільшення, так і до зменшення амплітуди частотних складових у фіксованому інтервалі частот. Розрахунки виконані для параметрів характерних щодо використання на даний час геофонів і найбільш поширених порід. Окремо розглянуто електродинамічний велосіметр і п'єзоелектричний акселерометр.

Наукова новизна. Зміни частотного складу, що зареєстровані геофоном у сейсмоакустичному сигналі, можуть бути обумовлені тільки зміною жорсткості на контакті геофону з гірською породою. Як індикатор можливого впливу жорсткості установки може виступати відношення частоти установки до власної частоти геофону. Запропоновані числові значення даного індикатора.

Практична значимість. Критичний аналіз отриманих раніше сейсмоакустичних даних з урахуванням можливої зміни жорсткості установки геофону в період вимірювань. Необхідність визначення частоти установки геофонів при їх першій установці та періодичного контролю даного параметра щодо подальшої експлуатації.

Ключові слова: шахтний геофон, сейсмоакустика, частотна характеристика, газодинамічні явища

Recommended for publication by A. Solodyankin, Doctor of Technical Sciences. The manuscript was submitted 09.12.20. 